paradigmas

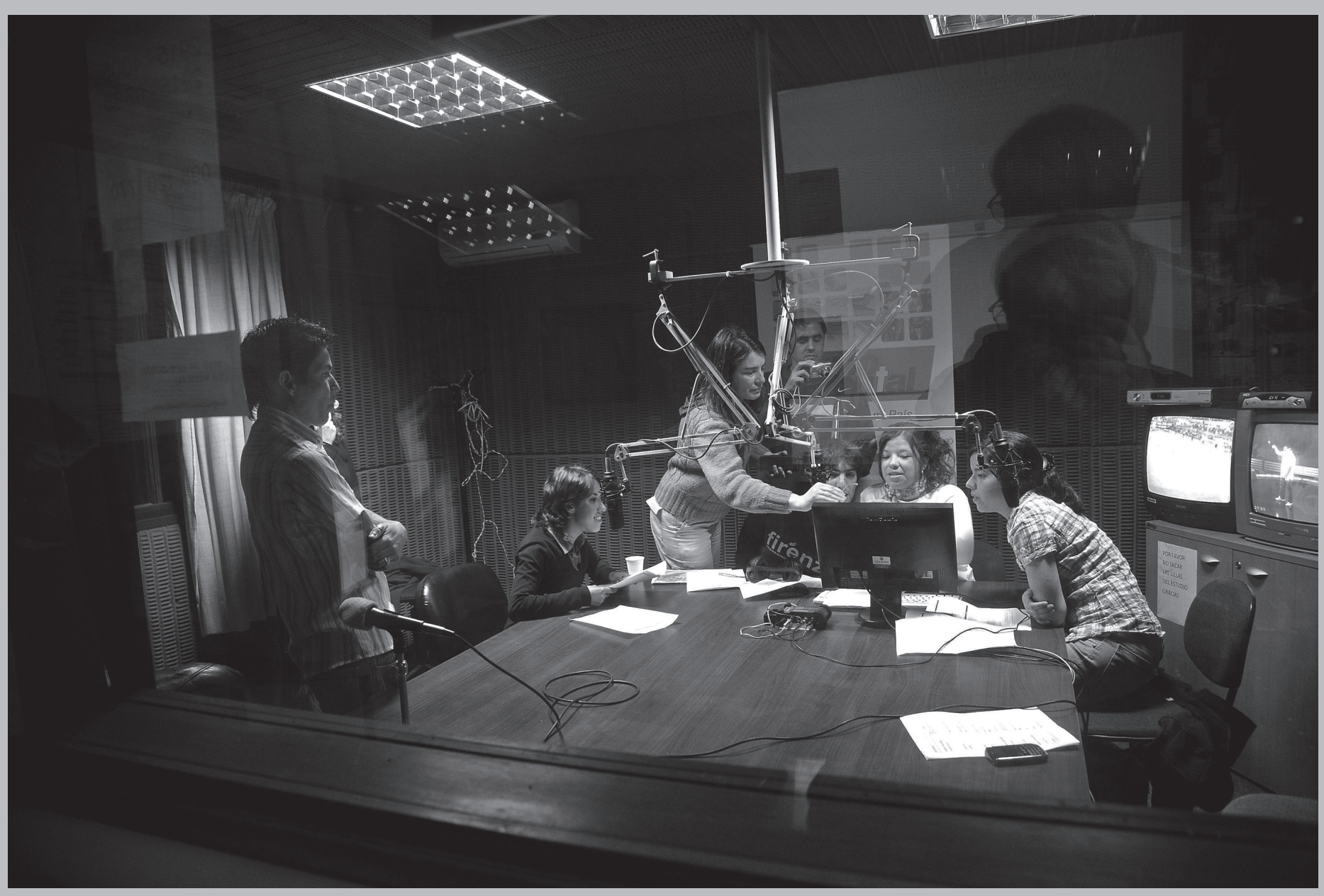




\title{
Código de barras
}

\author{
Por redacción de dixit
}

Foto de Alberto Pigola

\section{El concepto}

Código de barras es un programa radial que abre un canal de diálogo entre la sociedad civil y la realidad carcelaria. Una parte de los contenidos del programa se generan dentro de la cárcel La Tablada, a partir del trabajo en talleres con un grupo de internos; otros materiales son producidos por un equipo de jóvenes voluntarios -algunos estudiantes universitarios-, responsable de la edición. El programa en vivo es conducido por ex reclusos y voluntarios.

\section{El origen}

El proyecto surgió de la Fundación Entre Todos, que tiene como uno de sus objetivos mejorar la calidad de vida de las personas privadas de libertad. A partir de una idea de Javier Galdona, sacerdote a cargo de la Pastoral Penitenciaria y de la mencionada fundación, y de las propias inquietudes de los presos, las comunicadoras Mercedes Clara y Carla Lima armaron un equipo base de trabajo. "Nos interesó el proyecto, nos entusiasmó la sola posibilidad del proceso", relatan mientras van recordando cómo "de ahí en más todo fue una sorpresa: que tomaran con interés cada insumo que les llevábamos; que su mayor desvelo fuera conseguir formación en oficios para poder hacer algo al salir de la cárcel; que comenzaran a surgir poetas; que uno de ellos aprendiera a tocar la guitarra en la cárcel e hiciera muchas canciones, entre ellas la cortina actual del programa. Hoy los presos escriben proyectos con propuestas para su rehabilitación".

El proyecto se inspira en experiencias locales e internacionales que, si bien son diferentes, comparten la elección de la radio como medio privilegiado. "A nivel local hubo alguna experiencia de radio dentro de la cárcel, pero no que se emitiera en una radio comercial. En Texas (EEUU) existe una experiencia interesante que lleva muchos años en el aire; se trata de un programa dirigido a presos que es conducido por un ex preso", cuenta Mercedes Clara y señala, además, que lo que diferencia a Código de barras es que es un proyecto colectivo que se dirige a la sociedad civil.

\section{El equipo}

Las comunicadoras Mercedes Clara y Carla Lima, con formación en psicología social y pedagogía respectivamente, son las responsables de animar, coordinar y articular los procesos. Trabajan con dos colegas que acompañan el proceso en la cárcel y junto a un equipo de apoyo, formado por cinco voluntarios jóvenes y algunos voluntarios ex presos. "Velamos por el protagonismo de los internos en la gestión del programa, así como por la formación, concretamos talleres con especialistas en distintas áreas que contribuyan a fortalecer los equipos", explican.

\section{La metodología de trabajo}

Para realizar el programa radial, el equipo se basa en el trabajo desarrollado en la cárcel. Por una parte, se coordinan cursos y talleres -como, por ejemplo, comunicación radial, literatura, expresión oral y narrativa- y, posteriormente, los internos realizan entrevistas y trabajos de aplicación. Para este acercamiento con los reclusos, recuerdan las coordinadoras que no tomaron "precauciones de lenguaje ni actitudi-
Ficha técnica

Responsables del proyecto:: Carla Lima (posgrado y

licenciatura en Comunicación; posgrado en Pedagogía de los Medios) y Mercedes Clara

(licenciatura en Comunicación y Psicologia Social). Ambas gozaron de una beca del Consejo Episcopal

Latinoamericano (CELAM) sobre especialización en Comunicación para el trabajo pastoral.

Institución que enmarca el proyecto::

Fundación Entre Todos. Fecha de inicio de los talleres::

mayo de 2009 Fecha de comienzo de las emisiones radiales:: primera temporada octubrediciembre de 2010. Segunda temporada setiembre 2011enero 2012.

Emisión:

Radio Oriental, $770 \mathrm{AM}$ Domingos de 21:30 a 22:30 hs. 
Foto de apertura de Alberto Pigola:: (Montevideo, 1959) es profesor de fotografía en la Licenciatura en Comunicación Social de la Universidad Católica del Uruguay y en la Escuela Universitaria Centro de Diseño. Es fotógrafo y realizador audiovisual. afpigola@adinet.com.uy nales especiales. Fuimos advertidas sobre las palabras y la ropa que debíamos utilizar, pero no quisimos tomarlas en cuenta. Nos paramos sobre la idea de que somos iguales y que trabajamos entre adultos". En cuanto a las expectativas de los participantes, recuerdan que "al comienzo esperaban una postura más directiva, pero el trabajo realizado luego de estar trabajando desde 2009 permite ver los resultados en la participación y en cómo responde cada uno desde la autogestión”.

\section{Integración de los talleres}

Los insumos fundamentales del programa se obtienen del taller de comunicación radial, en el que participan alrededor de veinte internos, quienes realizan entrevistas al interior de La Tablada. Desde el inicio, las coordinadoras pidieron que la conformación de los talleres fuera heterogénea. "Solicitamos que pudieran acceder también personas que no se motivaban con el estudio porque consideramos que la comunicación y lo radial podrían ser motor para entusiasmarlos", relata Carla Lima. "Hoy sabemos que el trabajo en el taller de comunicación aporta a los maestros de primaria y secundaria de la cárcel, quienes expresan que los participantes del taller se motivan en la realización de otras tareas en el aula, mejoran la lectoescritura, la capacidad de trabajo en grupo y en la gestión de nuevas iniciativas y proyectos a la interna de la cárcel”.

\section{Los contenidos}

El principal material es la vida de los participantes. Los internos van seleccionando los temas y los preparan en informes, mesas redondas o entrevistas. Los contenidos son supervisados por las autoridades antes de la salida al aire: "en la Dirección Nacional de Cárceles se escucha todo antes de que se emita. Esto tiene consecuencias positivas a nivel individual y grupal", señalan las coordinadoras, y destacan que "siempre hemos trabajado con libertad y sabiendo que es un terreno donde hay que cuidar las formas, sin perder el arte de decir y contar la realidad".
"Desde la cárcel se piensa sobre la inseguridad ciudadana, el consumismo, la droga y las formas de restablecer una sociedad que se fragmenta. Poner en diálogo el tema de la fragmentación social, a partir de lo que viven y sienten las personas privadas de libertad, representa para los internos su posibilidad de estar en sociedad. El que escucha el programa se encuentra con personas que sueñan, que se inquietan, que buscan posibilidades y desarrollan capacidades; a través del programa quienes están en la cárcel ejercen el derecho de acceso a los medios de comunicación, y encuentran en estos oportunidades de humanización. Sostenemos que un espacio de comunicación con estas características es necesario para la democracia. Sin una mirada que integre la diversidad de perspectivas, seguiremos fragmentando la comprensión y las posibilidades de respuesta. Como afirma Paul Ricoeur, toda historia, aun la más estructural, está construida a partir de relatos”, señalan las coordinadoras del proyecto.

\section{La sustentabilidad}

El equipo de trabajo está compuesto íntegramente por voluntarios y el espacio radial es donado. Aun cuando existe un fuerte compromiso por parte de todos los actores del proyecto, las coordinadoras consideran que la principal dificultad es económica: "Todos los implicados tenemos la camiseta puesta y los ecos que recibimos del afuera son muy alentadores. Siempre que le hemos pedido una mano a alguien nos la ha dado, aun los profesionales con agenda llena se acercan a dar formación o ser entrevistados".

\section{Una experiencia para replicar}

Carla y Mercedes consideran que Código de barras es un proyecto que podría replicarse en otros establecimientos carcelarios. "Sería lindo multiplicar la experiencia a otros centros de reclusión y crecer en ese sentido, pero es un proyecto que requiere muchas horas de dedicación porque son muchos los procesos a cuidar y, por ser todos voluntarios, los tiempos son limitados". Al pensar en replicar la experiencia, 
señalan las coordinadoras, sería bueno integrar también a los guardias de la cárcel, en tanto "personas que sufren las vicisitudes del mundo de la prisión sin estar cumpliendo pena”.

\section{Los momentos del proceso}

Luego de dos años de estar trabajando en el proyecto, las coordinadoras reflexionan sobre los procesos individuales y grupales que han observado: "Vemos cambios evidentes en los participantes. Los que comienzan tienden a decir que no tienen nada que aportar, que no tienen la formación como para preparar los temas y las entrevistas. Con el transcurso del taller, se van apropiando de sus experiencias de vida y valorizan el entrono y su valía. Los integrantes que hace más tiempo que participan, proponen proyectos, muchos de los cuales se logran concretar. Nos impresiona que en las soluciones todos estamos de acuerdo: los internos le han presentado propuestas al Comisionado Parlamentario, al director Nacional de Cárceles, a senadores y en todos hay consenso".

Las coordinadoras constatan, además, otro rasgo fundamental: "La experiencia carcelaria puede ser una alternativa para el encuentro consigo mismo, pero el encuentro del encarcelado con la sociedad y los roles que puede asumir son materias pendientes. Y esto significa que el desarraigo que implica la privación de libertad puede reafirmar aquello que se busca evitar con la penalización”.

\section{Momentos de taller}

Las coordinadoras recuerdan algunos relatos de los presos participantes del proyecto. "Los muchachos de la cárcel manifiestan que al principio no encontraban las palabras para expresarse 'Uno pasa los días con un grupo reducido de compañeros, usando un máximo de 200 palabras, de las que 199 no son ni lindo ni querido', relató un participante en un taller", recuerda una de las coordinadoras. Uno de los participantes, "inquieto y sudoroso, en la primera etapa de su asistencia al taller contaba que hacía años que le había perdido la pista a su abogado de oficio. No sabía bien por cuál de sus delitos estaba, ni mucho menos qué tiempo le faltaba para cumplir la pena. El taller le resultaba un lugar en el que los compañeros le iban explicando sus derechos y posibilidades. Se consiguió un nuevo abogado, comenzó a escribir compulsivamente con ritmo y cadencia odas a la Ciudad Vieja, a su madre y a su hijo desconocido. Con el pasar del tiempo se fue enterando que le quedaba muy poca pena por cumplir. Nunca le pudimos quitar de la cabeza la idea de que Mercedes y Carla habían apelado por él ante el juez para que todo tomara forma. El taller desencadenó cosas en su vida y él las atribuyó todas a 'las profes'. Pero nosotras solo vamos los lunes a la cárcel, dos horitas".

\section{Escuchar y ser escuchado}

"Se pueden generar procesos desde las personas excluidas, desde sus palabras, desde sus maneras de sentir y entender las realidades que viven. Se trata de escuchar esas voces silenciadas, a veces hasta por los mismos discursos salvadores". La comunicación, en ese sentido, se renueva permanentemente: "Con la excusa de contarle a otros sobre nosotros, nos contamos a nosotros mismos quiénes somos y quiénes queremos ser", señala una de las coordinadoras del proyecto, y confirma su compañera: "en la elaboración de discursos sobre la propia realidad se fortalece la autoestima y una nueva mirada más reflexiva sobre sí mismo. Como afirma Hanna Arendt, el relato no es un fin sino una forma de constitución de la identidad, tanto individual como colectiva. ¿Cómo conocer lo que no se comunica? Lamentablemente, en lo desconocido se proyectan fantasías y, a veces, el desconocido es el depósito de miedos. En las personas presas este problema se exacerba. Como la identidad se construye socialmente, las narraciones son necesarias para ampliar los significados en la comunidad, en la cultura.

La emisión de un programa de radio puede aportar a la comunidad nuevos marcos de referencia, que le permitan generar pensamiento y otras formas de incidir en la construcción de la realidad”.:. 